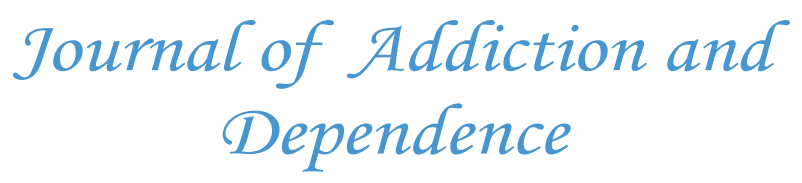

Mini review

\title{
Pethidine Abuse: A Novel Finding
}

\author{
Jamshid Ahmadi* \\ Substance Abuse Research Center, Shiraz University of Medical Sciences, Shiraz, Iran
}

*Corresponding author: Jamshid Ahmadi, MD, Professor of Psychiatry Founder and Director, Substance Abuse Research Center, Shiraz University of Medical Sciences, Shiraz, Iran, E-mail: Jamshid_Ahmadi@yahoo.com

\begin{abstract}
Background: Pethidine abuse is not a common problem.

Objective: The goal of this study is to explain management of pethidine withdrawal symptoms.

Results: Sublingual administration of a single high dose of buprenorphine is very useful for the treatment of pethidine withdrawal symptoms.

Discussion: This study indicates that administration of a single high dose of sublingual buprenorphine is very helpful in the treatment of pethidine withdrawal symptoms. Hence, this report could be a considerable addition to the literature.

Conclusions: It can be resulted that a single high dose of buprenorphine is very useful in the management of pethidine withdrawal symptoms. It looks that buprenorphine as a single high dose is as successful as daily low dose for a longer duration.
\end{abstract}

Keywords: Buprenorphine; Pethidine withdrawals
Received Date: March 14, 2016

Accepted Date: May 13, 2016

Published Date: May 15, 2016

Citation: Ahmadi, J. Pethidine Abuse: A Novel Finding. (2016) J Addict Depend 2(2): $72-74$.

DOI: $10.15436 / 2471-061 X-16-017$

\section{Introduction}

Buprenorphine is a safe drug and a partial mu receptor agonist. Its sublingual administration has low possibility of toxicity and overdose $\mathrm{e}^{[1,2]}$. Many studies, comparing buprenorphine with methadone, disclosed that buprenorphine is more effective than methadone ${ }^{[3-5]}$. In a research study, Johnson, Jaffe, and Fudala illuminated that $8 \mathrm{mg}$ of sublingual buprenorphine per day is comparable to $60 \mathrm{mg}$ of methadone per day considering retention rates and opioids negative urines ${ }^{[6]}$.

Oral administration of buprenorphine has little absorption but when is used sublingually is well absorbed, reaching $60 \%-$ $70 \%$ of the plasma concentration. Detoxification from buprenorphine is more comfortable than methadone. Buprenorphine in comparison to other opioids derivatives has less physiological dependency. It should be mention that buprenorphine can diminish the incidence of HIV and other associated disorders following opioids utilization ${ }^{[2,7,8]}$. Opium has a long history of medicinal and societal acceptance in some regions of the world, such as, North America, Europe and Asia ${ }^{[9,10]}$.

Physical and psychiatric disturbances are growing globally ${ }^{[1-28]}$. In mental problems, substance related disorders, especially opioids and stimulants connected problems have been shown as going up globally dilemma. Presently, opioids and stimulants-linked mental diseases are a developing problem and have resulted more referrals to emergency wards, psychiatric outpatient centers and inpatients centers ${ }^{[29-46]}$.

Pethidine is administered for the treatment of pain (usually for renal pain and labor pain). Pethidine abuse is not common. Some people abuse it to get high. Its withdrawal symptoms are similar to other opioids such as morphine. Presently, available treatment management plans for pethidine withdrawal symptoms are administration of narcotic medications such as buprenorphine and

Copyrights: (C) 2016 Ahmadi, J. This is an Open access article distributed under the terms of Creative Commons Attribution 4.0 International License. 
methadone or non-narcotic drugs like clonidine and NSAIDS ${ }^{[1]}$.

\section{Case Presentation}

In this study we describe a patient with pethidine dependence who successfully responded to a single dose of $66 \mathrm{mg}$ of buprenorphine. NA was a married 61years old retired teacher with Bachelor of Science in educational management. He lived with his family in capital city of Yasooj in Kohkilouyeh \& Bouyerahmad province in south of Iran.

He began intravenous injection of pethidine at age of 40 after an operation of disc herniation and also self-medication of his migraine headache. He step by step increased the dose of pethidine so that he had been abusing 10 ampoules (overall 1000 $\mathrm{mg}$ pethidine) per day since 6 months prior to admission. Since several years prior to admission he was abusing dexamethasone and chlorpheniramine ampoules on and off. He did not report smoking tobacco, opium, heroin or cannabis.

Due to pethidine abuse and depression he was admitted in psychiatric ward. In comprehensive psychiatric interview and mental status examination he was depressed and anxious. In physical and neurological examinations we could not reveal any significant abnormal findings. Urine drug screening tests were positive for morphine and benzodiazepine only. Tests for viral markers (HIV, HCV and HB Ag) were normal.

Based on comprehensive medical, psychiatric, and substance use history and also DSM-5 criteria, NA was diagnosed as "opioid induced depressive disorder and opioid (pethidine) use disorder. In hospital admission, we administered venlafaxine $225 \mathrm{mg}$ per day for the treatment of depression. On the second day of admission he complained of withdrawal pain and opioid craving, so we administered buprenorphine $66 \mathrm{mg}$ as a single dose only.

With reference to the close monitoring, precise measurement and interview ( 3 times a day) for pethidine withdrawal pain and craving, he reported a diminishing level of withdrawal symptoms and craving after administration of a single dose of $66 \mathrm{mg}$ of sublingual buprenorphine. Our patient was discharged without any pethidine withdrawal symptoms after 10 days of hospital admission.

\section{Discussion}

We commonly treat opioids (including pethidine) dependent patient with clonidine, methadone or buprenorphine in Iran. With reference to the current Iranian drug policy if somebody is found to be abusing illicit substances or illegal drugs (excluding tobacco products), such as, benzodiazepines, opioids, cannabis, ecstasy, methamphetamine, hallucinogens, cocaine or alcohol, they must be referred to the addiction treatment centers or psychiatric hospitals or private clinics to be treated.

Our report shows that administration of $66 \mathrm{mg}$ of sublingual buprenorphine as a single dose is very useful in the treatment of pethidine withdrawal symptoms. We should mention that our patient did not benefit from venlafaxine but improved with buprenorphine, because venlafaxine administration requires at least two weeks to be effective but buprenorphine administration needs only a few hours to apply its effects. Hence, this report could be a considerable addition to the literature.

\section{Limitations of the study}

In this work we reported a patient with abuse of pethidine who replied to a single high dose of buprenorphine. So we cannot generalize the result to all cases with pethidine. We require multicenter clinical trials to be able to generalize the findings.

\section{Conclusions}

It can be concluded that a single dose of $66 \mathrm{mg}$ of sublingual buprenorphine is useful in the management of pethidine withdrawal symptoms. For the treatment of pethidine withdrawal symptoms, it seems that buprenorphine as a single high dose is as effective as daily low dose for a longer duration.

Acknowledgement: None to be declared.

\section{Conflict of interests: Nil}

\section{References}

1. Sadock, B., Sadock, V., Ruiz. P., et al. Kaplan \& Sadock'S Synopsis of Psychiatry. (2015) Lippinott Wiliams and Wilkins, Philadelphia (USA).

2. Brian, J. Opium and infant-sedation in 19th century England. (1994) Health Visitor 67(5): 165-166.

3. Jasinski, D.R., Pevnick, J.S., Griffith, J. D. Human pharmacology and abuse potential of the analgesic buprenorphine: a potential agent for treating narcotic addiction. (1978) Arch Gen Psychiatry 35(4): 501-516. 4. Ling, W., Charuvastra, C., Collins, J.F., et al. Buprenorphine maintenance treatment of opiate dependence: a multicenter, randomized clinical trial. (1998) Addiction 93(4): 475-486.

5. Ling, W., Rawson, R. A., Compton, M. A. Substitution pharmacotherapies for opioid addiction: from methadone to LAAM and buprenorphine. (1994) J Psychoactive Drugs 26(2): 119-128.

6. Strain, E.C., Stitzer, M.L., Liebson, I. A., et al. Comparison of buprenorphine and methadone in the treatment of opioid dependence. (1994) Am J Psychiatry 151(7): 1025-1030.

7. Johnson, R.E., Jaffe, J.H., Fudala, P.J. A controlled trial of buprenorphine treatment for opioid dependence. (1992) JAMA 267(20): 27502755 .

8. Lewis, J.W. Buprenorphine. (1985) Drug Alcohol Depend 14(3-4): 363-372.

9. Jasinski, D.R., Fudala, P.J., Johnson, R.E. Sublingual versus subcutaneous buprenorphine in opiate abusers. (1989) Clini Pharmacol Ther 45(5): 513-519.

10. Jonnes, J. The rise of the modern addict. (1995) Am J public Health 85(8): 1157-1162.

11. Gill, D., Ahmadi, J., Pridmore, S. Suicide and Gambling on the Public Record. (2014) MJP 2 (1): 81-88.

12. Ahmadi, J., Ahmed, M.G., Bayoumi, F.A., et al. Mental Health of Dubai Medical College Students. (2012) Iran J Psychiatry Behave Sci 6(2): 79-83.

13. Ahmadi, J., Kamel, M., Ahmed, M.G, et al. Dubai Medical College students' scores on the Beck Depression Inventory. (2008) Iranian Red Crescent Journal (IRCMJ) 10(3): 169-172.

14. Pridmore, S., McInerney, G., Ahmadi, J., et al. Enlarged Virchow-Robin spaces in a psychotic woman. (2007) Journal of Psychiatric Intensive Care 3(1): 49-54.

15. Pridmore, S., Robinson, J., Ahmadi, J. Suicide for scrutinizers. (2007) Australas Psychiatry 15(3): 247-248.

16. Ghanizadeh, A., Kianpoor, M., Rezaei, M., et al. Sleep patterns and habits in high school Students in Iran. (2008) Ann Gen Psychiatry 13: $7: 5$. 
17. Ghanizadeh, A., Arkan, N., Mohammadi, M.R., et al. Frequency of and barriers to utilization of mental health services in an Iranian population. (2008) East Mediterr Health J 14(2): 438-446.

18. Pridmore, S., Ahmadi, J. Two cases of 'Type 3' suicide. (2010) Australas Psychiatry 18(5): 426-430.

19. Pridmore, S., Brüne, M., Ahmadi, J., et al. Echopraxia in schizophrenia: possible mechanisms. (2008) Aust N Z J Psychiatry 42(7): 565-571.

20. Pridmore, S., Ahmadi, J., Reddy, A. Suicide in the absence of mental disorder. (2012) Working Paper Of Public Health 6: 1-11.

21. Pridmore, S., Ahmadi, J., Majeed, Z.A. Suicide in Old Norse and Finnish folk stories. (2011) Australas Psychiatry. 19(4): 322-324.

22. Pridmore, S., Ahmadi, J. Usage of download of psychiatry by Muslim Countries. (2011) Bulletin of clinical psychopharmacology 21(2): 174.

23. Mani, A., Dastgheib, S.A., Chanoor, A., et al. Sleep Quality among Patients with Mild Traumatic Brain Injury: A Cross-Sectional Study. (2015) Bull Emerg Trauma 3(3): 93-96.

24. Pridmore, S., Ahmadi, J. Psalm 137 and Middle Cerebral Artery Infarction. (2015) ASEAN Journal of Psychiatry 16(2).

25. Pridmore, S., Ahmadi, J. Book reviews. (2005) Aust N Z J Psychiatry 39(3): 205-256.

26. Pridmore, S., Ahmadi, J., Evenhuis, M. Suicide for scrutinizers. (2006) Australas Psychiatry 14(4):359-364.

27. Khademalhosseini, Z., Ahmadi, J., Khademalhosseini, M. Prevalence of Smoking, and its Relationship with Depression, and Anxiety in a Sample of Iranian High School Students. (2015) Enliven: Pharmacovigil Drug Saf 1(1):005.

28. Ahmadi, J., Ahmadi, N., Soltani, F., et al. Gender differences in depression scores of Iranian and German medical students. (2014) Iran J Psychiatry Behav Sci 8(4): 70-73.

29. Ahmadi, J., Dastgheib, S.A., Mowla, A., et al. Treatment of Methamphetamine Induced Persistent Psychosis. (2016) J Add Pre Med 1(1): 103.

30. Ahmadi, J., Sahraian, A., Shariati, S., et al. Delusional disorder joined with opium dependence. (2015) Sch J App Med Sci 3(9D): 33873390.

31. Anvar, M., Ahmadi, J., Hamidian, S., et al. Female Sexual Dysfunction Among the Wives of Opioid-Dependent Males in Iran. (2016) Int J
High Risk Behav Addict 5(1): e25435

32. Ahmadi, J. Misuse of tablets of ephedrine, adult cold and cold stop to get high: A distinguished enigma. (2016) Int J Res Rep 2(2): 30-35.

33. Ahmadi, J. Methylphenidate in the treatment of methamphetamine withdrawal Craving: a novel outcome. (2016) J Drug Abuse 2(1): 12. 34. Ahmadi, J., Ghafoori, F., Rahimi, S. Management of heroin addiction with baclofen and clonidine. (2015) Int J Res Rep 1(1):1-5.

35. Ang-Lee, K., Oreskovich, M.R., Saxon, A.J., et al. Single dose of 24 milligrams of buprenorphine for heroin detoxification: an open-label study of five inpatients. (2006) J Psychoactive Drugs 38(4): 505-512.

36. Kutz, I., Reznik, V. Rapid heroin detoxification using a single high dose of buprenorphine. (2001) J Psychoactive Drugs 33(2):191-193.

37. Ahmadi, J., Khoddaman, A.R., Kordian, S., et al. Treatment of an obese opioid dependent with a single dose of $80 \mathrm{mg}$ of buprenorphine: A new opening. (2016) Int J Res Rep 2(1):11-18.

38. Ahmadi, J, Ahmadi., F, Torabi., A, et al. A single dose of $55 \mathrm{mg}$ of buprenorphine for the treatment of heroin dependence: a new result. (2016) J Harmoniz Med Res and Hlth Sci 3(1): 1-7.

39. Ahmadi, J. Instant Detoxification of Heroin with High Dose of Buprenorphine. (2016) J Addiction Prevention 4(1): 3.

40. Ahmadi, J., Sarani, E.M., Jahromi., M.S., et al. Treatment of heroin dependence with $40 \mathrm{mg}$ of buprenorphine: a novel passageway. (2016) Int J Original Res 2(2): 68-73.

41. Ahmadi, J. Non-opioid drugs in the management of tramadol dependence: A novel approach. (2016) Int J Original Res 2(2): 40-45.

42. Ahmadi, J, Ahmadi., F, Ahmadi., F, et al. A firsthand launch: Heroin dependence treatment with a single dose of $48 \mathrm{mg}$ of buprenorphine. (2016) Landmark Res J Med Med Sci 3(2): 019-022.

43. Ahmadi, J. Combination of analgesics (NSAIDS), baclofen, clonidine and a single dose of buprenorphine for heroin detoxification. (2016) IJPSR 7(2): 92-96.

44. Ahmadi, J. Fast Treatment of Methamphetamine Related Anxiety and Depressive Disorders: A Novel Approach. (2016) J Addict Med Ther Sci 2(1): 044-046.

45. Ahmadi, J. Treatment of cannabis related psychosis with electroconvulsive therapy (ECT): a rapid approach. (2016) J Harmoniz Res Med and Hlth Sci 3(1): 44-50.

46. Ahmadi, J. Recurrent psychosis related to methamphetamine. (2016) J Harmoniz Res Med and Hlth Sci 3(1): 51-55.
Ommega Online Publishers

Journal Title: Journal of Addiction and Dependence(JAD)

Journal Short Name: J Addict Depend
ISSN no: 2471-061X

E-mail: addiction.depend@ommegaonline.org

Website: www.ommegaonline.org 